\title{
Ferramenta de análise de produtos inteligentes e interativos
}

\author{
- Ana Veronica Pazmino \\ UFSC, Brasil \\ ana.veronica@ufsc.br \\ - Rodrigo Braga \\ UFSC, Brasil \\ rodrigo.braga@ufsc.br
}

Analysis tool for smart and interactive products

\begin{abstract}
This paper aims to demystify the term of interaction and intelligence to be applied with appropriate conceptual basis. Currently there are a lot of innovative products called interactive or intelligent, when in fact nothing but responsive products and low interaction. This paper presents the theoretical foundations of interaction levels and smart design (related to artificial intelligence), then it shows the deconstruction and analysis of interactive products through specific criteria. The result item is a tool for analyzing interactive and intelligent products.
\end{abstract}

Keywords: Interaction Design, Smart Design, Innovation

\section{Introdução}

Produtos contemporâneos estão sofrendo uma revolução com a ajuda da tecnologia da informação, tecnologias de automação e Inteligência Artificial, e como consequência estes vem se tornaram sistemas complexos que combinam hardware (microprocessadores, sensores, unidades de armazenamento de dados), software e conectividade em inúmeras formas. Esses "produtos inteligentes, interativos e conectados" abriram uma nova era no desenvolvimento de produto, inovação e na competitividade de mercado local e global.

Nos dias de hoje, com mais frequência, a indústria vem buscando ofertar produtos inteligentes e conectados, tecnologias que estão ampliando exponencialmente as oportunidades para criar novas funcionalidades, elevando a confiabilidade, aumentando a utilização e desenvolvendo capacidades que atravessam e transcendem as fronteiras tradicionais entre os produtos.

Nesta onda, alguns fabricantes devido à automatização de alguns processos no produto, conectividade ou apenas um design diferenciado, vários produtos estão sendo denominados smart, inteligentes e interativos. Neste contexto, o problema de pesquisa que se apresenta é: as máquinas que vem sendo comercializadas como smarts ou inteligentes e interativos, são realmente "inteligentes e interativos"?

Neste contexto, o objetivo desta pesquisa foi tentar achar as respostas para as seguintes perguntas: Como podemos classificar os produtos comerciais relacionados à sua "inteligência" e interatividade? Seria possível classificar estes produtos apenas com os dados comerciais fornecidos pelo fabricante? E ainda, é possível fazer algum tipo de classificação sem poder testar o produto?

- Os objetivos específicos deste trabalho foram:

- Definir o design de interação e os níveis de interação;

- Definir o smart design e os níveis de inteligência;

- Analisar produtos inteligentes e interativos;

- Propor uma ferramenta instrumental de análise para produtos inteligentes e interativos;

Para alcançar os objetivos da pesquisa, foi realizada uma investigação documental sobre design de interação e inteligência artificial e um levantamento de produtos comerciais em que foi possível identificar que máquinas de lavar, aspiradores de pó robôs, computadores, smartphones, entre outros que na sua maioria responsivos, coativos e proativos, mas não inteligentes. Eles foram projetados para reagir de um modo atento, adaptativo e proativo à presença e atividades de pessoas, a fim de satisfazer as suas necessidades e desejos.

Atualmente uma geladeira, um assento de avião um smartphone ou uma peça de roupa que incorpore tecnologias complexas para trazer benefícios que melhorem o trabalho, o lazer, a aprendizagem estão sendo denominados "inteligentes".

Muitos produtos espertos possuem tecnologia eletrônica que visa satisfazer as necessidades e o comportamento do 
usuário. Os produtos "inteligentes" tem a possibilidade de cumprir muitas funções (amplitude) de forma a superar as expectativas dos clientes, por meio de uma "interação natural". O design "inteligente" pode influenciar nas emoções através da visão, do toque ou do uso, isto é o resultado de um projeto que possibilita que as necessidades que temos ou nem imaginamos ter possam ser superadas.

Estes produtos ou sistemas têm um alto desempenho e respostas para o bem-estar: pode ajudar em uma urgência médica, em escutar uma bela música, em ter uma noite boa de sono, conversar com os filhos quando eles estão longe, em brincar ativamente. Para a pesquisa foram pesquisados diversos produtos e selecionados 5 produtos exemplos e estabelecidos critérios de análise para analisar os graus de interação e inteligência, também foram aplicadas as ferramentas análise funcional e estrutural para desconstruir os produtos/sistemas. E finalmente é proposta uma ferramenta para facilitar a desconstrução/classificação de produtos.

\section{Design de interação}

Como o desenvolvimento tecnológico dos últimos dez anos, o design de interação se configura como uma área do campo do design visa facilitar o uso dos produtos e sistemas tecnológico pelos usuários. Para contextualizar a área a seguir são definidos alguns termos relacionados ao design de interação. MOGGRIDE e VERPLANK (1994) (apud BURDEK, 2006 p.409) definiram o design de Interação como o projeto de um produto digital (quer hardware ou software), envolvendo o projeto das estruturas de ação que indicam ao usuário um procedimento de uso.

PREECE (2005) define o design de interação (IxD) como o projeto de produtos ou serviços interativos que fornecem suporte as mais diversas atividades cotidianas das pessoas. $O$ design de interação visa criar experiências que melhorem a maneira como as pessoas interagem quando: trabalham, se divertem, se comunicam etc.

PALACIOS (2000 apud MONTEZ \& BECKER, 2005) afirma que o adjetivo interativo é aplicável a qualquer sistema ou objeto quando o seu funcionamento permite ao usuário algum nível de participação, suposta participação ou troca de ações. Montez \& Becker (2005) ressaltam ainda que, por este motivo, o termo interatividade virou marketing de si mesmo, a ponto de perder a precisão de sentido, visando somente seduzir o consumidor, espectador ou usuário, dando a ele alguma possibilidade ou sensação de participação ou interferência.

SCHMITT (2000, p. 74) define as experiências como acontecimentos individuais que ocorrem como resposta a algum estímulo, e são o resultado de uma observação direta ou participação nos acontecimentos - reais imaginários ou virtuais. O autor ainda afirma que as experiências não são espontâneas, mas induzidas, ou seja, possui referencial e intencionalidade.

A experiência está ligada a uma fonte cognitiva de informações, como percepção, memória, imaginação, sensações, e possuí um modo de ser próprio representando o estado mental do indivíduo. Sob esta premissa, a experiência está diretamente relacionada ao conhecimento.

Pode-se compreender a experiência consciente como um processo comunicativo que se estabelece na relação reversível entre um organismo (a pessoa) e seu ambiente (mundo vivido).

\section{Tipos e níveis de interação}

Os tipos e níveis de interação dependem dos fatores que contribuem para a interatividade. Para STEUER (1994) os três principais fatores que contribuem para a interatividade são:

- Tempo de resposta: é período de uma mensagem gasta para se tornar efetiva ou for assimilada pelo sistema. A interação instantânea caracteriza o mais alto valor dessa variável.

- Amplitude: refere-se ao número de atributos que podem ser manipulados em um determinado momento, isto é, a quantidade de modificações que o usuário pode realizar.

- Mapeamento: é a capacidade do sistema em representar graficamente o controle das modificações no sistema.

Lippman (apud Montez \& Becker, 2005) apresentou cinco características necessárias para que um sistema pudesse ser classificado como interativo:

- Interruptabilidade: o usuário pode interromper o processo e atuar quando desejar. Esta característica aproxima o processo interativo de uma conversa, onde o fluxo de informações flui de modo inteligente.

- Granularidade: ligada diretamente à característica anterior, a granularidade refere-se ao menor elemento após o qual se pode interromper o processo. A granularidade impede que os usuários tenham a impressão que o sistema esteja travado e pode ser entendida, no caso de uma conversa, seria o final de uma frase, um questionamento feito ou um gesto com a cabeça, por exemplo.

- Degradação suave: é o comportamento de uma instância do sistema quando em determinado momento não há resposta possível de ser dada. Ao invés do sistema bloquear ou deixar o usuário sem a resposta procurada, deve ser possível aprender quando e como pode ser obtida a resposta não disponível naquele momento.

- Previsão limitada: interligada à característica anterior, a condição de responder ao usuário, mesmo quando a indagação não esteja presente na programação, dará a impressão de um banco de dados infinitos.

- Não default: o sistema não deve forçar a direção a ser seguida pelos seus participantes, se aproximando das características de um sistema com navegação não linear. Os níveis e tipos de interação tratam do processo de interação entre os integrantes (usuário x sistema) e da qualidade da relação que emerge da ação entre eles. Vários autores têm identificado vários tipos de interação. Para Primo (2007) existem dois tipos de interação:

- Interação reativa: que se caracteriza pela troca mais automatizada, processos de simples ação e reação. 
A relação entre uma máquina e um usuário em que a máquina já possui uma proposta elaborada e as condições de troca são predeterminadas, ou seja, as trocas encontram-se previstas no projeto. A previsibilidade é a característica deste tipo em que "o usuário terá de se adaptar as ações exigidas agindo dentro das condições e dos limites previstos".

- Interação mútua: está baseada na construção cooperativa da relação, cuja evolução repercute nos eventos futuros. Neste tipo existem intercâmbios nos quais pouco ou nada está definido a priori. Uma conversa via Skype ou uma conversa via whatsap emergem no momento que são criadas pelos usuários durante o encontro.

Normam (2010) identifica a Interação natural (Natural Interaction) trata de interagir com dispositivos eletrônicos por meio dos 5 sentidos, seja por meio de gestos, comandos de voz, movimentos e expressões corporais ou detecção e identificação de partes do corpo humano como rosto, mão, polegar, retina, articulações, entre outros. O seu propósito, é tornar a experiência do usuário mais próximo de contextos e diálogos do cotidiano, sem a necessidade de aprendizado de novos procedimentos, comandos, linguagens ou dispositivos eletrônicos. A interação com o sistema vem sendo feita de diversas maneiras, entre elas, por toque em telas touch, reconhecimento de gestos, de posições específicas, detecção da face do usuário ou reconhecimento de voz.

Para Normam (2010) a interação natural atua no nível do subconsciente, sem esforço, no qual a comunicação em ambas às direções se faça tão naturalmente, tão facilmente, que o resultado seja uma fusão harmônica de pessoa e máquina, realizando em conjunto uma tarefa. Os sinais de um produto interativo devem ser naturais, que informem sem perturbar, não intrusivas, não irritantes.

Outra distinção é feita por Braviano (2008):

- Baixo: Caracterizado pelouso de estruturas arborescentes, como as disponibilizadas pelos caixas automáticos, no momento em que o usuário deseja retirar dinheiro ou obter o extrato de sua conta bancária. Neste tipo de categoria podem-se citar os sistemas onde em uma parte específica da tela, o usuário tem a possibilidade de visualizar algo diferente (comum no uso de aparelhos de televisão ou softwares específicos), já que, mesmo de maneira simples, existe certo grau de não linearidade.

- Médio: Operações de manipulação constituem um tipo mais elaborado de interatividade, como os sistemas de simulação em que o usuário tem determinadas liberdades de caminhos, apesar de não poder atuar sobre determinados elementos do sistema, tais como imagens de fundo, árvores, carro, manchas de óleo na pista, em simuladores de condução de veículos.

- $\quad$ Alto: Quando a manipulação do conteúdo não está mais sujeita a estruturas já realizadas, mas é orientada à produção destas.

Reisman (2002) (apud Montez, 2005) classificou em três os níveis de interatividade, em ordem de abrangência, baseando- se em uma nomenclatura utilizada por Schwier \& Misanchuk, em 1993:

Reativo: quando as opções e os feedbacks são dirigidos pelo sistema, p.ex. um retorno de luz, ou som para indicar que está ligado, ou fazendo o processamento;

Coativo: quando o usuário tem controle sobre sequências, ritmos e estilos. Existe uma ação x resposta simultânea e continua, p. ex. selecionar uma impressora, selecionar o tipo de papel, selecionar o número de cópias etc.;

Proativo: quando o usuário pode controlar tanto a estrutura quanto o conteúdo. Maior tipo de atributos, no menor tempo de resposta e para um nível maior cognitivo.

Para analisar produtos interativos, serão utilizados os fatores e características de forma a determinar o nível de interação que o sistema oferece.

\section{Smart design}

Smart design ou design "inteligente", consideramos uma área multidisciplinar que abrange o design e a engenharia que se destaca no desenvolvimento de produtos mais interativos e estuda a aplicação da inteligência artificial nestes produtos. Especialistas nesta área devem possuir habilidades e compreensão necessárias para desenvolver novos produtos e sistemas, utilizando tecnologias inovadoras, emergentes. São objetos com interação, significado e tecnologia. Um produto que não apenas funciona, mas que surpreende e encanta.

Segundo Norman (2010) os produtos não são inteligentes, a inteligência vem dos projetistas que programaram suas funções. Se considerarmos que Inteligência vem do latim intelligentia que é a capacidade humana de resolver problemas através do pensamento abstrato. Envolvendo memória, raciocínio, seleção de dados, interpretação, entendimento, etc. e que Inteligência artificial é o campo de estudo que visa construir um sistema que reproduza o pensamento humano, ou seja, capaz de desenvolver um comportamento inteligente. Dessa forma, teríamos poucos produtos possuem inteligência artificial.

Segundo GRINYER (2001) Produtos "inteligentes" basicamente reúnem 6 fatores: Tecnologia complexa, Alto Significado, Intuição, Emoção, Interação e Boa experiência. A Tecnologia Complexa envolve produtos que possuem um sistema automatizado que introduz um novo conjunto de tarefas ou ações. O Significado é o efeito concretamente experimentado pelo usuário no processo da leitura de um objeto. A Intuição trata do conhecimento imediato, que independe do raciocínio. Apreendida no contexto, no ambiente social, baseada na experiência. A Emoção trata da perturbação do espírito provocada por situações diversas e que se manifesta como alegria, tristeza, raiva, etc. a interação natural é a ação que se exerce mutuamente entre duas ou mais coisas, ou duas ou mais pessoas de forma natural (simbiose) troca de ações. E a boa experiência provoca no usuário vivencias e emoções por meio dos sentidos. A experiência é individual e depende do repertório pessoal. 
Produtos "inteligentes" oferecem o que o usuário nunca imaginou que poderia precisar. Alguns termos que estão surgindo como a domótica (no Brasil o termo mais utilizado é Automação Industrial) que é a união da palavra (Domus), casa, com (Robótica), que está relacionada ao ato de automatizar. Tem por objetivo satisfazer as necessidades de comunicação, segurança e conforto das pessoas nas casas.

Nesta linha surgem as casas inteligentes, que é um espaço residencial que com soluções integradas baseadas nas tecnologias de informação e domótica de modo a oferecer uma infraestrutura tecnológica avançada que usufruir de uma vasta gama de aplicações e serviços, tais como: segurança, gestão de energia, conforto, automação de tarefas domésticas, teletrabalho, teleassistência, operação e manutenção local e remota, entre muitas outras já disponíveis ou a disponibilizar no futuro a partir dos avanços tecnológicos e de estilo de vida. Casa Inteligente possui três pilares fundamentais, que são o design, a tecnologia e a ecologia.

A Domótica inteligente não é simplesmente uma residência dotada de controle central. Uma casa inteligente é algo como uma residência com vida própria com características de um sistema inteligente, interagindo com os habitantes da residência, aprendendo dinamicamente com seus comportamentos. Este aprendizado é permanente, pois os habitantes estão sempre mudando.

Desde o início dos anos 60, a inteligência artificial (IA) encontrou diversas aplicações industriais - na maior parte das vezes na área de decisão baseada em conhecimento para o projeto e a monitorização de produtos industriais ou processos. Esse fato foi realçado com avanços na informática, no advento de computadores pessoais e da Internet, desta forma muitas aplicações práticas de técnicas de inteligência artificial foram realizadas (Rezende, 2005).

Dada a impossibilidade de uma definição formal precisa para IA, visto que para tanto seria necessário definir primeiramente a própria inteligência foram propostas algumas definições operacionais, como por exemplo: "uma máquina é inteligente se ela é capaz de solucionar uma classe de problemas que requerem inteligência para serem solucionados por seres humanos" (McCarthy \& Hayes, 1969). "Inteligência Artificial é a parte da ciência da computação que compreende o projeto de sistemas computacionais que exibam características associadas quando presentes no comportamento humano a inteligência" (Barr \& Feigenbaum, 1981); ou ainda a "Inteligência Artificial é o estudo das faculdades mentais através do uso de modelos computacionais" (Charniak \& McDermott, 1985). Outros se recusam a propor uma definição para o termo e preferem estabelecer os objetivos da IA: "tornar os computadores mais úteis e compreender os princípios que tornam a inteligência possível" (Winston, 1984). A inteligência artificial não se resume a raciocinar, decidir, aprender, planear, mas também em "como integrar estes processos no seio de uma única entidade" (Rezende, 2005).

Inicialmente, existiam duas linhas principais de pesquisa para a construção de sistemas inteligentes: a linha conexionista e a linha simbólica. A linha conexionista visa à modelação da inteligência humana através da simulação dos componentes do cérebro, isto é, dos seus neurônios e das suas interligações. O modelo conexionista deu origem a área de redes neuronais artificiais (Bittencourt, 1998). A linha simbólica segue a tradição lógica, ou seja, modela a inteligência com o uso de formalismo lógico, e tem em McCarthy e Newell seus principais defensores (Bittencourt, 1998).

Além da linha conexionista e simbólica observa-se hoje o crescimento de uma nova linha de pesquisa em IA baseada na observação de mecanismos evolutivos encontrados na natureza, tais como, a auto-organização e o comportamento adaptativo. Nesta linha os modelos mais conhecidos são os algoritmos genéticos e os autômatos celulares (Bittencourt, 1998).

Desta forma, pode-se sintetizar que as principais linhas de pesquisa para a construção de sistemas inteligentes são:

- Simbólica: utiliza formalismos do tipo lógico para simular o comportamento inteligente expresso através da linguagem. É a base para os sistemas periciais e para os sistemas baseados em lógica difusa.

- Conexionista: visa à modelação da inteligência humana através da simulação dos componentes do cérebro, isto é, de seus neurônios, e de suas interligações. É a base para as Redes Neuronais (RN).

- Evolutiva: simula a evolução natural para encontrar soluções para problemas complexos. É a base para métodos de otimização tais como os Algoritmos Genéticos e para a Vida Artificial.

Conforme se observa a dificuldade em uma definição formal, Russell e Norvig (2003) identificam que as definições variam em duas dimensões, ilustrados pela Figura 1, onde a parte superior relaciona-se ao processo de pensamento e raciocínio. Já a parte inferior ao comportamento, enquanto as definições do lado esquerdo medem o sucesso em termos de fidelidade ao desempenho humano o lado direito refere-se ao sucesso quando comparado a um conceito ideal de inteligência (racionalidade).

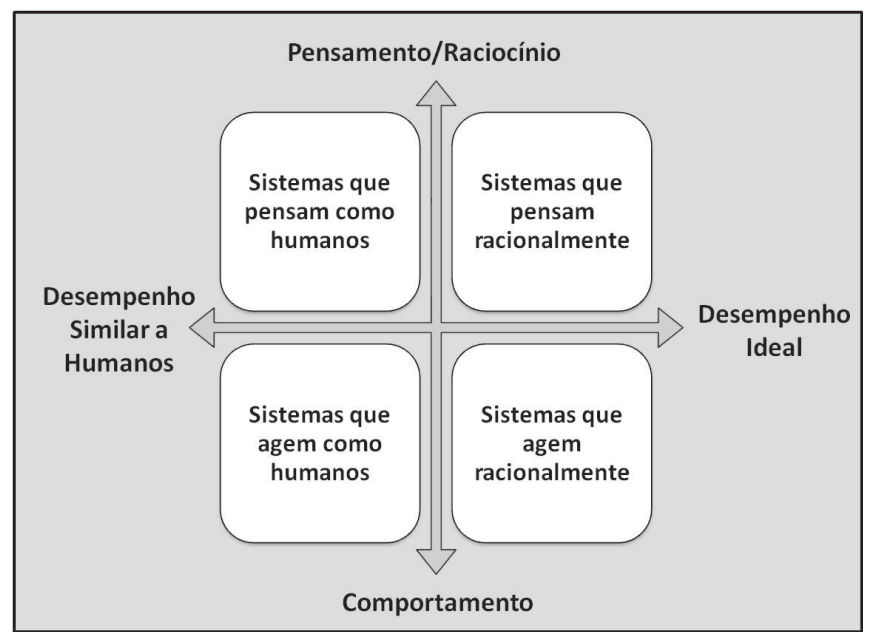

Figura 1: Dimensões de sistemas inteligentes. 
Podem-se citar alguns exemplos de IA, dentre as diversas aplicações: Processamento de linguagem natural; Reconhecimento de padrões; Desenvolvimento de sistemas especialistas; Criação de simuladores; Planejamento automatizado e escalonamento; Aplicações de Algoritmos genéticos; Sistemas Multiagentes (Sistema em que dois ou mais agentes interagem ou trabalham em conjunto de forma a desempenhar um determinado conjunto de tarefas).

Devido a IA ser tão complexa este artigo propõe uma métrica com base na escala de inteligência humana de David Wechsler em 1955. Segundo (KLEINMAN, 2012) a escala de inteligência adulta (Wechsler Adult Intelligence Scale) WAIS sofreu algumas modificações e atualmente é conhecida como WAIS III. Sendo o método padrão dos testes de Q.I.

Na escala de inteligência Wechsler a pontuação média é de 100 pontos e tem os seguintes níveis:

- Abaixo de 69: inteligência extremamente baixa;

- 70 -79: limítrofe;

- 80-89: média baixa;

- 90-109: média;

- 110-119: média alta;

- 120-129: superior;

- Acima de 130: extremamente superior.

\section{Agentes}

Ao falar de inteligência artificial cabe mencionar os agentes, para Benyon (2011), são processos de computador autônomos e ativos que tem alguma habilidade de se comunicar com pessoas e/ou outros agentes e de adaptar seu comportamento. Agente é simplesmente algo que age, do latim agere que significa fazer.

Beyon (2011) menciona que existem dois tipos de agentes: os que conhecem uma pessoa eagem em nomedela, permitindo a personalização e adaptação de sistemas às preferências, aos hábitos e conhecimentos habituais. E os que conhecem determinados tipos de trabalho, como programação de prazos, indexação, verificação de ortografia etc. tecnologias preditivas como a dos sistemas de texto tentam antecipar palavras.

Os robôs são exemplos de interação baseada em agente, os robôs industriais e domésticos estão se tornando mais comuns. Os robôs industriais incluem sistemas pré-programados, como os que são utilizados na fabricação de carros. Os robôs domésticos incluem cortadores de grama, aspiradores de pó.

\section{Propriedades / características para agentes inteligentes} Varias características servem para identificar agentes inteligentes:

- Adaptabilidade: deve ser capaz de ajustar-se aos hábitos, métodos de trabalho e preferências de seus usuários;

- Autonomia: capacidade de operar separadamente e decidir o que fazer enquanto opera separadamente;

- Benevolência: suposição de que os agentes não têm objetivos contraditórios e que todo agente sempre tentará fazer o que lhe é solicitado;

- Colaboração: um agente não deve aceitar (e executar) instruções sem considerações, ele deve levar em conta que o usuário humano comete erros, omite informações importantes e/ou fornece informações ambíguas. Neste caso, um agente deve checar estas ocorrências fazendo perguntas ao usuário. Deve ser permitido a um agente recusar executar certas tarefas que possam sobrecarregar a rede ou causar danos a outros usuários;

- Comunicabilidade/Habilidade social: capacidade de se comunicar com outros agentes, usuários, objetos e ambiente;

- Degradação Gradual: capacidade de executar parte de uma tarefa quando existe incompatibilidade na comunicação ou domínio. No contexto das noções de risco, agentes trabalham melhor quando apresentam esta característica;

- Flexibilidade: um agente deve ser capaz de fazer uma escolha dinâmica das ações e da sequencia de execução das mesmas, em um determinado estado do ambiente;

- Inteligência: conjunto de recursos, atributos e características que habilitam o agente a decidir que ações executar, bem como a capacidade de tratar ambiguidades. O raciocínio desenvolve-se através de regras, conhecimento e evolução artificial;

- Mobilidade: é a habilidade de um agente se mover pela rede;

- Planejamento: é a habilidade de sintetizar e escolher entre diferentes opções de ações desejadas para atingir os objetivos;

- Pró-Atividade: um agente deve exibir oportunismo e comportamento direcionado a objetivos;

- Reatividade: um agente deve perceber o ambiente e responder às modificações que ocorrerem nele;

- Representabilidade: um agente deve representar o usuário em suas ações.

\section{Tipos de agentes}

- Colaborativos: Focalizam autonomia e cooperação (com outros agentes) para executar suas próprias tarefas. Eles podem aprender, mas não é dada muita ênfase a esta característica em suas operações. Geralmente agentes colaborativos podem negociar para alcançar um consenso sobre alguma questão.

- De Interface: Enfatizam autonomia e aprendizado para executar suas tarefas. Agentes de interface são agentes que interagem com o usuário, recebendo especificações do usuário e entregando resultados.

- Móveis: Agentes móveis são programas escritos tipicamente em uma linguagem script, o qual pode ser despachado remotamente de um computador cliente e transportado para um computador servidor para a sua execução.

- De Informação: Agentes de informações são agentes que acessam uma, e potencialmente muitas fontes de informações, e são capazes de colecionar e manipular informações obtidas destas fontes para responder 
consultas solicitadas pelo usuário ou outros agentes.

- Reativos: São agentes que executam tarefas quando estas são solicitadas pelo usuário, ou seja possuem determinado comportamento quando estimulados.

- Híbridos: Agentes híbridos são os agentes que combinam a filosofia de um ou mais tipos de agentes.

- Sistemas Heterogêneos: Sistemas de Agentes Heterogêneos referem-se a um conjunto de dois ou mais agentes, os quais pertencem a duas ou mais classes de agentes diferentes. Um sistema de agente heterogêneo pode também conter um ou mais agentes híbridos. Sistemas de Agentes Heterogêneos também são entendidos como sistemas multi-agentes.

- Autônomos: Agentes autônomos são agentes que podem interagir independente e efetivamente com seus ambientes. Não precisam necessariamente do usuário.

Um agente é um sistema computacional, situado num dado ambiente (Real ou Virtual), que tem a percepção desse ambiente através de sensores e age de forma autônoma nesse ambiente através de atuadores de forma a desempenhar uma dada função. Estes devem se aperceber do ambiente (sensores), decidir a ação a executar em cada instante ("pensar") e executar a ação com os seus atuadores no ambiente.

Todas as propriedades que um agente apresenta devem estar implícitas em sua arquitetura. A arquitetura de um agente pode ser definida como uma metodologia particular para definir agentes. Ela especifica como o agente pode ser decomposto na construção de um conjunto de módulos componentes e como estes módulos podem interagir. $O$ conjunto dos módulos e suas interações devem prover uma resposta para a questão de como os sensores de dados e o estado interno corrente do agente determinam suas ações e futuros estados internos. Uma arquitetura abrange técnicas e algoritmos para suportar esta metodologia. (Maes, 1991 in Wooldridge, et al., 1995)

"As arquiteturas podem ser divididas em três áreas: a arquitetura deliberativa (abordagem clássica do Paradigma de IA), a arquitetura reativa (abordagem alternativa) e arquiteturas híbridas (utiliza ambas as abordagens)." (WOOLDRIDGE et al., 1995).

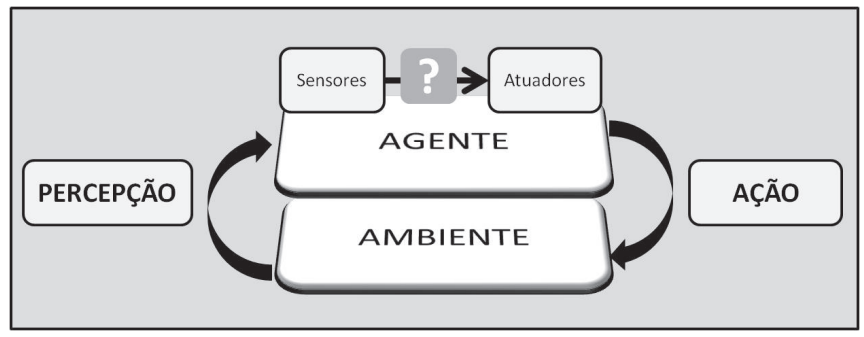

Figura 2: Arquitetura abstrata de um agente.

Com base em várias bibliográficas, podem-se resumir os tipos de arquitetura dos agentes em:

- $\quad$ Reativos simples
- Reativos baseado em modelos (reativos com memória)

- Agentes de procura

- Baseados em Objetivos

- Baseados na utilidade

- Com Heurística

- Baseados em conhecimento

- Com Aprendizagem

- Adaptativos

- Híbridos

Segundo o conceito, de uma máquina inteligente, proposto por Alan Turing (1950), esta precisaria ter as seguintes capacidades:

- Processamento de linguagem natural;

- Representação de conhecimento;

- Raciocínio automatizado;

- $\quad$ Aprendizado de máquina;

- Visão de computador;

- Robótica.

A seguir são apresentados alguns produtos denominados no mercado como "inteligentes e interativos".

\section{Análise de Produtos}

Nesta sessãoéapresentado um resumo dealguns produtos comerciais ditos inteligentes e interativos e as características disponibilizadas pelos anunciantes. Posteriormente serão analisados segundo os critérios de interação e inteligência relatados nos itens anteriores:

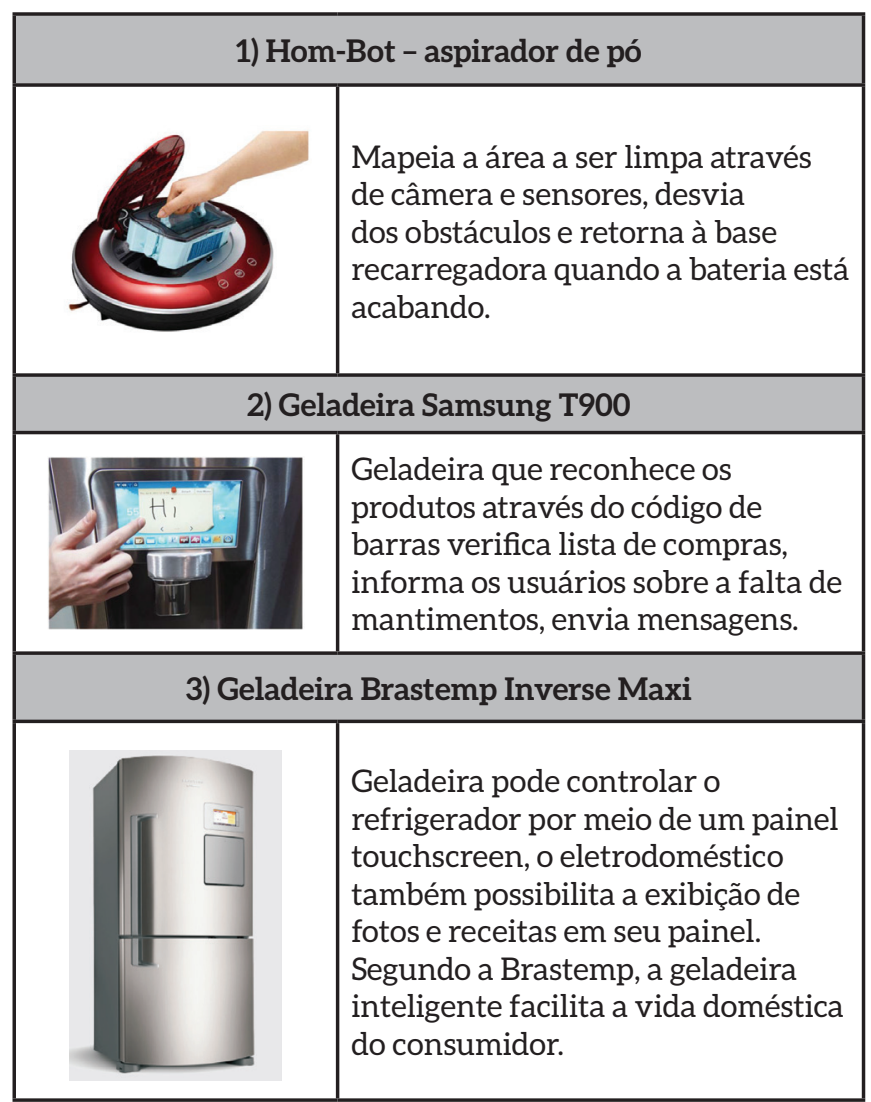




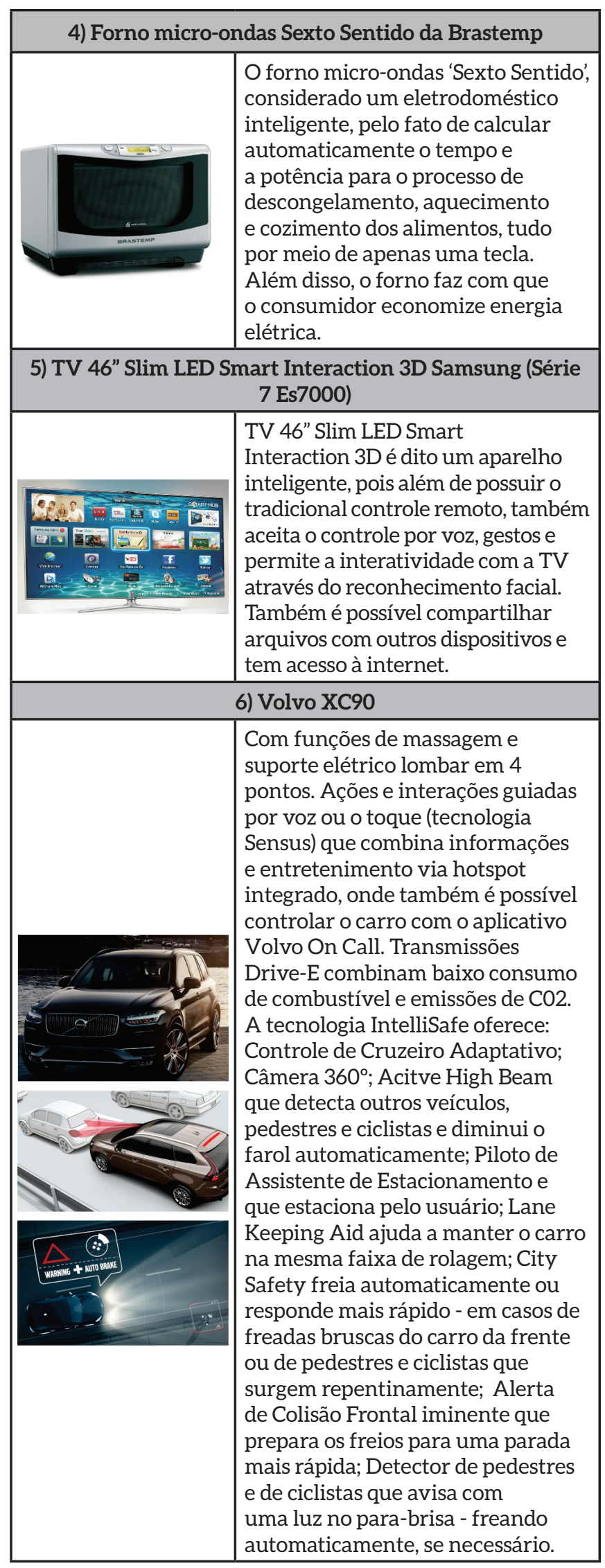

Quadro 1: Produtos interativos e inteligentes.
Para a análise de interação se propõe uma matriz de inter-relação com os tipos de interação e os fatores para a interatividade. A tabela 1 mostra a matriz.

Devido às possibilidades de análise dos produtos, verificou-se a necessidade de criar classes de avaliação com base nos dados disponíveis para a classificação dos produtos. Por exemplo, dados obtidos dos anúncios comerciais fornecidos pelo fabricante onde a análise se apresenta de forma superficial, designada aqui por classe 3 de avaliação do QII. A tabela 2 mostra as classes sugeridas, onde a classe 1 é uma análise do produto com informações técnicas construtivas, já a classe 2 com base em testes funcionais do produto.

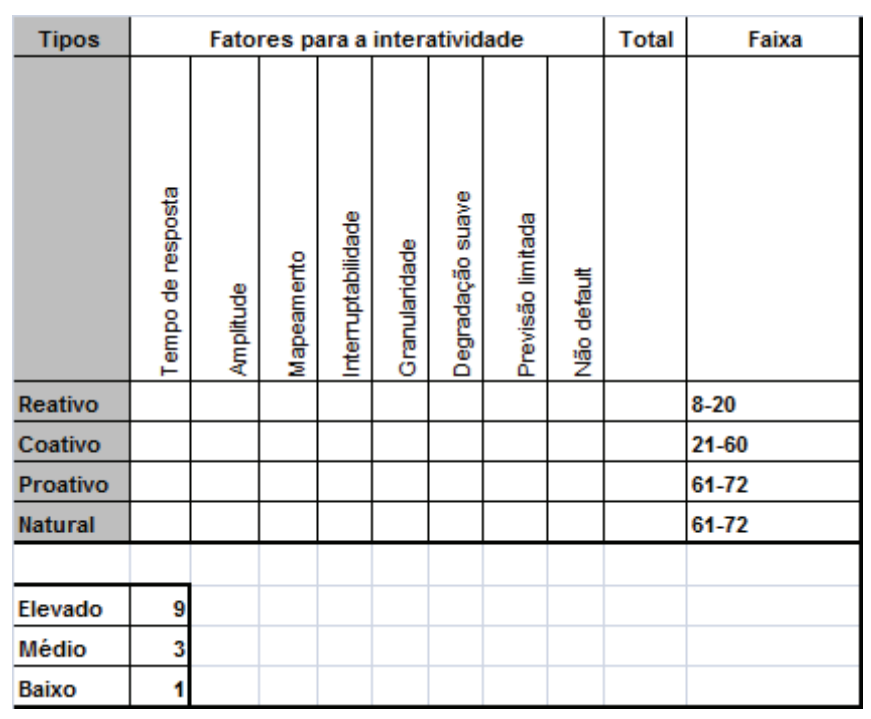

Tabela1: Matriz de avaliação da interação.

Um produto que alcance de 8-20 pontos será denominado reativo, com 21-60 coativo, de 61-72 proativo ou natural. Cabe salientar que a pontuação indica o maior atendimento ao quesito. Por exemplo: no caso de tempo de reposta se ele for rápido a pontuação será elevada.

\begin{tabular}{|c|c|}
\hline Classe & Avaliação com base em dados: \\
\hline 1 & Técnicos construtivos \\
\hline 2 & Experiencial \\
\hline 3 & Informacional/comercial \\
\hline
\end{tabular}

Tabela 2: Classes de Avaliação do QII.

Para a análise da inteligência se propõe uma matriz de inter-relação com os níveis de inteligência de Wechsler com as capacidades de Turing, características baseadas nas arquiteturas dos agentes inteligentes e algoritmos desenvolvidos nas diversas metáforas.

A tabela 3 mostra a matriz, onde a mesma sugere os valores máximos e mínimos quando tal característica é observada no produto.

Na tabela 4 a avaliaçãodos produtos sugeridos, normalmente 
anunciados como smarts ou inteligentes verificou-se, através da ferramenta proposta, que a maioria deles são classificados como de inteligência extremamente baixa na avaliação classe 3. Já na tabela 5 na interação se mostram na sua maioria como coativos. Como a interação é uma ação de mão dupla, seria necessário realizar uma análise da atividade dos mesmos com um grupo focal para identificar a interação e verificar a sua avaliação.

Da mesma forma, observada na análise da interação, seria necessário realizar uma análise dos produtos em funcionamento para identificar melhor o nível de inteligência e a interação, denominada, neste trabalho, de uma análise classe 2 .

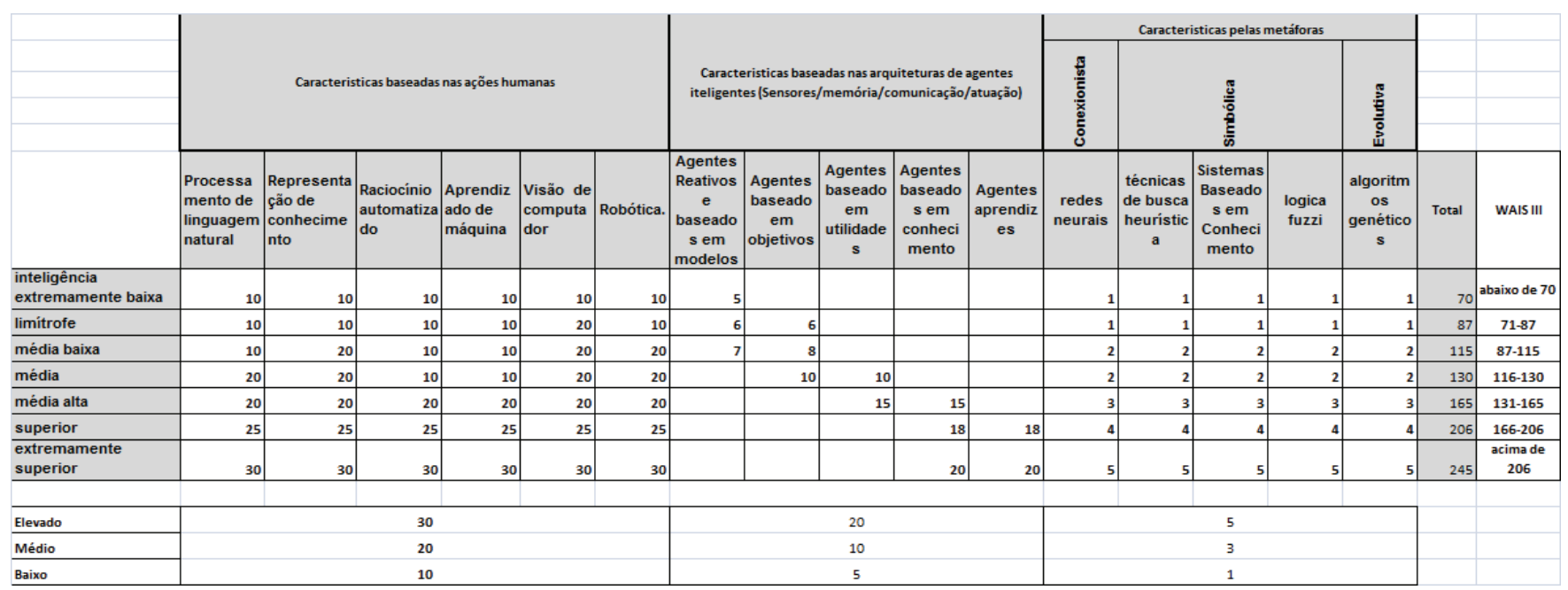

Tabela 3: Matriz de avaliação da inteligência.

\begin{tabular}{|c|c|c|c|c|c|c|c|c|c|c|c|c|c|c|c|c|c|c|c|}
\hline Produto & $\begin{array}{c}\text { Processa } \\
\text { mento de } \\
\text { linguagem } \\
\text { natural }\end{array}$ & $\begin{array}{c}\text { Representa } \\
\text { ção de } \\
\text { conhecime } \\
\text { nto }\end{array}$ & $\begin{array}{c}\text { Raciocínio } \\
\text { automatiza } \\
\text { do }\end{array}$ & \begin{tabular}{|c|} 
Aprendiz \\
ado de \\
máquina
\end{tabular} & $\begin{array}{c}\text { Visão de } \\
\text { computa } \\
\text { dor }\end{array}$ & Robótica. & \begin{tabular}{|c|} 
Agentes \\
Reativos \\
e \\
baseado \\
s em \\
modelos
\end{tabular} & $\begin{array}{c}\text { Agentes } \\
\text { baseado } \\
\text { em } \\
\text { objetivos }\end{array}$ & \begin{tabular}{|c} 
Agentes \\
baseado \\
em \\
utilidade \\
$\mathbf{s}$
\end{tabular} & $\begin{array}{c}\text { Agentes } \\
\text { baseado } \\
\text { s em } \\
\text { conheci } \\
\text { mento }\end{array}$ & $\begin{array}{c}\text { Agentes } \\
\text { aprendiz } \\
\text { es }\end{array}$ & $\begin{array}{c}\text { redes } \\
\text { neurais }\end{array}$ & \begin{tabular}{|c|} 
técnicas \\
de busca \\
heuristic \\
a
\end{tabular} & $\mid \begin{array}{c}\text { Sistemas } \\
\text { Baseado } \\
\text { s em } \\
\text { Conheci } \\
\text { mento }\end{array}$ & $\begin{array}{l}\text { logica } \\
\text { fuzzi }\end{array}$ & \begin{tabular}{|c|} 
algoritm \\
os \\
genético \\
$\mathrm{s}$
\end{tabular} & Total & $\begin{array}{c}\text { Nivel de } \\
\text { inteligênci } \\
\text { a }\end{array}$ & QII \\
\hline $\begin{array}{l}\text { Hom-Bot - aspirador } \\
\text { de pó }\end{array}$ & & 20 & 10 & & 20 & 20 & 7 & 6 & & & & & & & & & 83 & Limítrofe & $79 \times 28$ \\
\hline $\begin{array}{l}\text { Geladeira Samsung } \\
\text { T900 }\end{array}$ & & 10 & 10 & & & & & & & & & & & & & & 20 & $\begin{array}{l}\text { extremam } \\
\text { ente baixa }\end{array}$ & $20 \times 54$ \\
\hline $\begin{array}{l}\text { Geladeira Brastemp } \\
\text { Inverse Maxi }\end{array}$ & & 10 & & & & & & & & & & & & & & & 10 & \begin{tabular}{|l|} 
extremam \\
ente baixa
\end{tabular} & $10 \times 54$ \\
\hline $\begin{array}{l}\text { Forno micro-ondas } \\
\text { Sexto Sentido da } \\
\text { Brastemp }\end{array}$ & & 20 & 20 & & & & & & & 15 & & & & & & & 55 & $\begin{array}{l}\text { extremam } \\
\text { ente baixa }\end{array}$ & $55 \times 66$ \\
\hline $\begin{array}{l}\text { TV 46" Slim LED Smart } \\
\text { Interaction 3D } \\
\text { Samsung (Série } 7 \\
\text { Es7000) }\end{array}$ & 30 & 20 & & & 30 & & 10 & & & & & & & & & & 90 & $\begin{array}{l}\text { Média } \\
\text { baixa }\end{array}$ & $90 \times 66$ \\
\hline Volvo XC90 & 30 & 20 & 15 & & 30 & 15 & 10 & & & 15 & & & 3 & & & & 138 & Média Alta & $138 \mathrm{x}$ \\
\hline
\end{tabular}

Tabela 4: Avaliação da inteligência dos produtos do quadro 1.

\begin{tabular}{|c|c|c|c|c|c|c|c|c|c|c|}
\hline \multirow[t]{2}{*}{ Produtos } & \multicolumn{8}{|c|}{ Fatores para a intera tividade } & \multirow[t]{2}{*}{ Total } & \multirow{2}{*}{$\begin{array}{l}\text { Niveis de } \\
\text { interação }\end{array}$} \\
\hline & 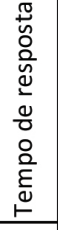 & 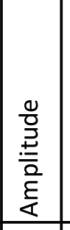 & 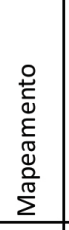 & 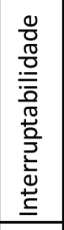 & 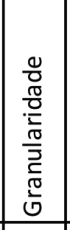 & 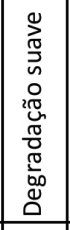 & 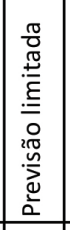 & $\begin{array}{l}\frac{\pi}{3} \\
\frac{\pi}{\pi} \\
\frac{\pi}{0} \\
0 \\
0 \\
2 \pi \\
2\end{array}$ & & \\
\hline Hom-Bot - aspirador de pó & 3 & 3 & 3 & 3 & 3 & 1 & 1 & 3 & 20 & Reativo \\
\hline Geladeira Samsung T900 & 9 & 9 & 9 & 9 & 9 & 3 & 3 & 3 & 54 & Coativo \\
\hline $\begin{array}{l}\text { Geladeira Brastemp Inverse } \\
\text { Maxi }\end{array}$ & 9 & 9 & 9 & 9 & 9 & 3 & 3 & 3 & 54 & Coativo \\
\hline $\begin{array}{l}\text { Forno micro-ondas Sexto } \\
\text { Sentido da Brastemp }\end{array}$ & 9 & 3 & 9 & 9 & 9 & 9 & 9 & 9 & 66 & Coativo \\
\hline $\begin{array}{l}\text { TV 46" Slim LED Smart } \\
\text { Interaction 3D Samsung } \\
\text { (Série } 7 \text { Es7000) } \\
\end{array}$ & 9 & 9 & 9 & 9 & 9 & 9 & 9 & 3 & 66 & Coativo \\
\hline Volvo XC90 & 9 & 9 & 9 & 9 & 9 & 9 & 9 & 9 & 72 & Proativo \\
\hline
\end{tabular}

Tabela 5: Avaliação da interação dos produtos do quadro 1. 


\section{Conclusão}

Conclui-se que quanto mais presente está a ação do usuário, no sentido de agir sobre as informações disponibilizadas, podendo manipular conteúdos e produzi-los, maior é o grau de interatividade do sistema.

Desta forma, o potencial de interatividade está intimamente associado à tecnologia que o usuário está usando. A interatividade surge quando o ambiente permite a seus usuários escolherem os elementos que desejam acessar, na ordem e no momento em que desejam tomar conhecimento destes. Quanto mais profunda a interatividade, mais profunda será a experiência de imersão do usuário, que se expressa na sua concentração, atenção, compreensão da informação e na sua interação instantânea e contínua com o conteúdo do sistema. A pesquisa ofereceu bases conceituais de uma ferramenta para análise e desconstrução de produtos interativos, visando auxiliar o desenvolvimento de produtos.

\section{Referencias}

Barr, A; Feigenbaum, E. (1985). The Handbook of Artificial Intelligence. Los Altos, California: William Kaufmann Inc, 1981, vol. I-II.

Benyon, David. (2011). Interação humano-computador. São Paulo: Person Prentice Hall.
Bittencourt, G. (1998). Inteligência artificial distribuída. I Workshop de Computação do ITA, Instituto Tecnológico de Aeronáutica.

Charniak, E; McDermott D. (1985). Introduction to Artificial Intelligence. Addison-Wesley Pub-lishing Company.

Grinyer, Clive. (2001). Smart Design: Products that change our lives. Rotovision. Switzerland.

Kleinman, Paul. (2015). Tudo que você precisa saber de psicologia: um livro prático sobre o estudo da mente humana. Editora gente: São Paulo.

McCarthy, J; Hayes P. (1969)Some philosophical problems from the standpoint of artificial intelligence, I. D. M. a. B. Meltzer, Ed. Edinburgh, GB: Edin-burgh University Press.

Montez, C., Becker, V. (2005). TV digital interativa: conceitos, desafios e perspectivas para o Brasil. Florianópolis: EdUFSC.

Norman, D. (2010). O design do futuro. Ed. Rocco: Rio de Janeiro.

Preece, J., Rogers, Y., Sharp, H. (2005). Design de interação: além da interação homem- computador. Porto Alegre: Bookman.

Rezende, S. O. (2005). Sistemas inteligentes: fundamentos e aplicações. SP-Brasil: Manole.

Smith, Gillian. (2007). What is Interaction Design? In Designing Interactions. Org. MOGGRIDGE, Bill. MIT Press, London.

Winston, P. H. (1984). Artificial Intelligence, $2^{\text {ath }}$ ed.. MA: Addison-Wesley Publishing Company Reading 